\title{
Information Characteristics and Errors in Expectations: Experimental Evidence
}

\author{
Constantinos Antoniou, Glenn W. Harrison, Morten I. Lau, and \\ Daniel Read*
}

\begin{abstract}
We design an experiment to test the hypothesis that, in violation of Bayes' rule, some people respond more forcefully to the strength of information than to its weight. We provide incentives to motivate effort, use naturally occurring information, and control for risk attitude. We find that the strength-weight bias affects expectations but that its magnitude is significantly lower than originally reported. Controls for nonlinear utility further reduce the bias. Our results suggest that incentive compatibility and controls for risk attitude considerably affect inferences on errors in expectations.
\end{abstract}

\section{Introduction}

Behavioral finance explains market anomalies by drawing on evidence from psychology that some people respond to information in a systematically biased manner. However, several studies show that behavioral biases are not always robust when tested in tasks that reward subjects for being accurate. We design an experiment to test a psychological hypothesis, first proposed by Griffin and Tversky (GT) (1992), related to errors in expectations that is widely cited in finance.

According to the GT (1992) hypothesis, information can be broadly characterized along two dimensions: strength and weight. Strength is how saliently the information supports a specific outcome, and weight refers to its predictive validity. GT suggest that, in violation of Bayes' rule, some decision makers pay too much attention to strength and too little attention to weight, and thus overreact to high-strength, low-weight signals and underreact to low-strength, high-weight

*Antoniou (corresponding author), constantinos.antoniou@wbs.ac.uk, Read, daniel.read@wbs .ac.uk, Warwick Business School, University of Warwick; Harrison, gharrison@gsu.edu, Robinson College of Business, Georgia State University; and Lau, mla.eco@cbs.dk, Copenhagen Business School and Durham University Business School, Durham University. Harrison is also affiliated with the School of Economics, University of Cape Town. We thank Elena Asparouhova (the referee), Hendrik Bessembinder (the editor), and conference and seminar participants at the 2012 Academy of Behavioral Finance and Economics (NYU-Poly), the 2010 Foundations and Applications of Utility, Risk and Decision Theory (Newcastle, U.K.), and Warwick Business School. 
ones. The magnitude of the bias reported by GT is significant; in some cases, probabilities that should be equal under Bayes' rule diverged by $28 \%{ }^{1}$

Because the reported strength-weight hypothesis can parsimoniously explain both underreaction and overreaction, it has several applications in finance. Barberis, Shleifer, and Vishny (BSV) (1998) use the GT (1992) findings as the basis of a theory that explains several asset pricing anomalies. Liang (2003) and Sorescu and Subrahmanyam (2006) similarly use the GT findings to explain the pricing of earnings surprises and analyst recommendations, respectively. Other finance studies that cite GT to behaviorally explain their findings include Daniel and Titman (2006), Hackbarth (2009), de Dreu and Bikker (2012), Puetz and Ruenzi (2011), and Gupta-Mukherjee (2013).

However, there is tension in the literature about whether such behavioral biases are as significant as initially reported in tasks with an incentive-compatible reward system. For example, Grether (1980) and Charness, Karni, and Levin (2010) report that violations of Bayes' rule reduce substantially among financially motivated subjects. $^{2}$

We test the strength-weight hypothesis using an incentive-compatible design to encourage effort in the experimental tasks. ${ }^{3}$ In addition, to avoid confusion that may arise from subjects being asked to imagine signals from a hypothetical process, as GT (1992) asked their subjects to, we generate all the relevant information in front of our subjects during the experiment using physical urns and dice. ${ }^{4}$ Finally, in our experiment we elicit subjective beliefs using revealed preference, as opposed to the stated-preference methods used by GT, and revealed preference avoids the need for introspection. ${ }^{5}$

Our elicitation methods are based on the principles of subjective probability elicitation initially outlined by Ramsey (1931) and Savage (1954), (1971). Our respondents observed information signals generated by random draws from urns and chose between bets that varied the payoffs they offered if different states of the world were true. From these bets, we inferred the underlying subjective probabilities for the different states of nature and examined whether they were influenced by the strength-weight heuristic.

${ }^{1}$ GT ((1992), p. 415, Table 1) report that the elicited probability after a high-strength, low-weight signal with Bayesian posterior equal to $88 \%$ is $92.5 \%$ (5th row), whereas the elicited probability after a low-strength, high-weight signal with the same posterior is $64.5 \%$ (11th row), for a difference of $28 \%$.

${ }^{2}$ Several other authors have reported smaller biases in experimental economics conditions, such as Conlisk (1989), Plott and Zeiler (2005), Laury, McInnes, and Swarthout (2009), Cason and Plott (2014), and Andersen, Harrison, Lau, and Rutström (2013).

${ }^{3}$ GT (1992) paid $\$ 20$ to the respondent whose judgments "most closely" matched the correct values; this is not an incentive-compatible elicitation method.

${ }^{4} \mathrm{An}$ important advantage of this physical procedure is that it allows subjects to truly experience random draws from the latent process they are asked to estimate. In contrast, the hypothetical methods used by GT (1992) require that the experimenter artificially selects the outcomes, and as shown by Asparouhova, Hertzel, and Lemmon (2009), such selective sampling can significantly affect inferences about behavioral biases.

${ }^{5}$ Methods of introspection have been treated with skepticism by economists (Ramsey (1931), Smith (1982), and Gilboa, Postlewaite, and Schmeidler (2008)), perhaps because it is common for subjects to state a particular belief but act in a way that contradicts this statement (Costa-Gomes and Weizsäcker (2008), Rutström and Wilcox (2009)). 
Because subjects' choices depend on both subjective beliefs and preferences, in our estimations, we use data from a separate experimental task to control for the distorting effect of the utility function on inferences about subjective beliefs, estimating the relevant parameters using a structural model. We start our analysis assuming risk neutrality $(\mathrm{RN})$, moving on to a subjective expected utility (SEU) specification that allows for nonlinear utility. This approach allows us to examine whether inferences on decision heuristics are affected when one relaxes the assumption of $\mathrm{RN}$ that is commonly employed in experiments (e.g., Grether (1980)).

We find that, in violation of Bayes' rule, the magnitude of the probability update is higher after high-strength, low-weight signals than after lower-strength, higher-weight signals, with an average strength-weight bias of $6.05 \%$. This result confirms the findings of GT (1992) and suggests that the strength-weight bias is a plausible theory of errors in expectations. However, in our analysis, the strength-weight bias is less than a third of the bias reported by GT, which suggests that its effect on economic behavior is weaker than that suggested by the original estimates.

We also examine whether the strength-weight bias differs among subjects with different demographic characteristics. We find that female subjects deviate more strongly from the Bayesian benchmark, consistent with the findings of Charness and Levin (2005). We also find that the behavior of subjects who study in a quantitative field is more in line with Bayes' rule, consistent with the findings reported by Halevy (2007). However, knowledge of statistics does not completely offset the strength-weight bias.

Contrary to the findings of GT (1992), we do not find any evidence of overreaction to information. Rather, our results reveal a general tendency of underreaction or "conservatism" in the spirit of Edwards (1968). The degree of underreaction is higher when signal weight is higher. For example, for signals that imply a posterior of 0.88 , underreaction is $25 \%$ when the signal is of high weight and $17 \%$ when it is of low weight. This finding can explain underreaction-type phenomena in stock markets, whereby prices respond slowly to high-weight information, such as earnings surprises (Bernard and Thomas (1989)) or changes in dividend policy (Michaely, Thaler, and Womack (1995)).

We find that assumptions about attitude toward risk significantly affect inferences about the strength-weight bias. Specifically, when we assume RN, we find that the average bias is $11.1 \%$, whereas when we allow for nonlinear utility, the bias almost halves to $6.05 \%$. This implies that studies that investigate decision heuristics assuming RN could substantially mischaracterize any bias. Moreover, controls for risk attitude highlight behavioral patterns that would be difficult to identify otherwise. For example, we find that females are more risk averse and less Bayesian than males. Without controls for risk attitudes, it would be impossible to understand such differences. Overall, these results highlight the methodological point that risk attitude exerts a nontrivial effect on subjects' behavior in the laboratory and should be accounted for to describe behavior accurately. ${ }^{6}$

\footnotetext{
${ }^{6}$ Antoniou, Harrison, Lau, and Read (2015) also document that inferences regarding Bayesian updating change considerably when one controls for the utility function. However, they do not investigate the strength-weight bias.
} 
Because of the complexities of real-world markets, experimental methods are well placed to make contributions to the debate on systematic errors in expectations. Bondarenko and Bossaerts (2000) examine whether expectations in experimental markets are formed in accordance with Bayes' rule. Bloomfield and Hales (2002) and Asparouhova et al. (2009) test whether people make forecasts using historical information in a biased manner. Kuhnen and Knutson (2011) and Kuhnen (2015) analyze whether biases in beliefs are affected by emotions and whether they depend on whether the decision is taken in the domain of losses or gains, respectively. Our study contributes to this literature by testing whether the strength-weight effect is a plausible theory of errors in expectations in financial decisions.

The remainder of this article is organized as follows: Section II describes the experimental methods, Section III presents and discusses the results, and Section IV concludes the paper.

\section{Experimental Methods}

We recruited 111 respondents from the University of Durham, U.K. All received a $£ 5$ show-up fee. Payments for the experiment totaled $£ 2,692$, for an average payment of $£ 24.26$ per subject. Internet Appendix A (available at www .jfqa.org) shows demographic information about the subjects.

Our experiment included two tasks: the belief task, in which choices were made that allowed us to infer subjective probabilities, and the risk task, where subjects made choices over lotteries with known probabilities that allowed us to estimate their utility function. The full instructions used for these tasks are reproduced in Internet Appendices B and C.

In the belief task, there were two equally likely mutually exclusive states of the world. Respondents were provided with relevant sample information using urns and dice, after which they chose between pairs of acts (or "bets") that offered different payoffs, depending on which state of the world was actually obtained. Subjective probabilities were inferred from the pattern of acts chosen. Specifically, in the belief task, we first made a random choice between a blue and a white cup, which was concealed from the subjects. Both of these cups contained $N 10$ sided dice, where $N$ varied from trial to trial $(3,5,9$, and 17). The $N$ dice in the white cup had 6 white and 4 blue sides, and the $N$ dice in the blue cup had 6 blue and 4 white sides. We then rolled all the dice in the chosen cup and announced the outcome. ${ }^{7}$ Thus, the prior of each cup without information is $50 \%$, and after subjects observe the sample information, they must revise their expectations accordingly.

In each session, respondents saw 30 samples: 4 samples of 3 dice (i.e., $N=3$ ), 14 samples of 5 dice, 6 samples of 9 dice, and 6 samples of 17 dice. The distribution of sample sizes was chosen to roughly equalize the frequency of the least likely sample distributions. Signal weight is the size of each sample of dice rolls $(N)$, and signal strength is the difference between the number of dice

\footnotetext{
${ }^{7}$ To keep experimenters honest in the minds of the respondents, a subject from each session was randomly chosen to act as a "monitor" who supervised the rolling and counting of dice and announced the outcomes. The monitor received a flat payment of $£ 10$ for the belief task.
} 
showing a white face $(w)$ and those showing a blue face $(b)$ as a proportion of $N, \operatorname{abs}(b-w) / N$. A sample of $3 w$ and $0 b$, for example, has weight $=3$ and strength $=1$, whereas a sample of $10 \mathrm{w}$ and $7 b$ has weight $=17$ and strength $=3 / 17$. Both samples, however, have equal diagnosticity, with Bayes' rule giving a posterior of 0.77 . Nonetheless, GT (1992) report that stated probabilities for the high-strength, low-weight samples were higher than those for the Bayesianequivalent low-strength, high-weight samples.

After the sample information was announced, respondents placed "bets" on white and blue, using a decision sheet adapted from Fiore, Harrison, Hughes, and Rutström (2009), shown in Figure 1. Respondents were asked to conceptualize the task as one of making 19 separate bets with a different "bookies," each offering different odds. Effectively, the subject must use his or her subjective probability to compute how much a bet on white or blue for each bookie is worth and then choose the most favorable option. For example, assume that the subject believes that the probability of blue is $73 \%$. Assuming $\mathrm{RN}$, for the first bookie, this probability implies that the value of a bet on white is $0.27 \times 60=16.2$, which is greater than the value of a bet on blue $(0.73 \times 3.15=2.3)$. This subject would therefore prefer to bet on white for bookies 1-5 and then to bet on blue for remaining bookies $6-19 .{ }^{8}$ From observing the subject's betting choices, we can back out his or her latent subjective probability. ${ }^{9}$

If subjects are not risk neutral, however, the valuation of each bet will not use expected value, which can significantly affect inferences on inferred subjective probabilities (Kadane and Winkler (1988)). Returning to our previous example, assume now that the agent who placed a bet on blue for bookies 1-5 is risk averse, with preferences described by expected utility theory (EUT) and constant relative risk aversion (CRRA) as follows:

$$
u(x)=y^{1-r} /(1-r) .
$$

Assuming $r=0.5$, this betting behavior would imply that the subject's subjective probability of blue ranges between $60 \%$ and $65 \%$. Thus, the specification of the utility function will affect inferences about subjective probabilities and can therefore alter conclusions about the magnitude of the strength-weight effect.

Following Andersen, Fountain, Harrison, and Rutström (2014), we control for the distorting effect of the utility function on subjective probabilities using data from the risk task, which implemented the classic experimental design of Hey and Orme (1994). In this task, all respondents made a series of 20 choices between two lotteries with known probabilities. ${ }^{10}$

To incentivize subjects to exert effort in the experiment, we use the random lottery procedure, whereby one choice made by the subjects in both the risk and the belief tasks is selected randomly and played out for real money.

\footnotetext{
${ }^{8}$ Some subjects switched more than once, which of course violates SEU. Such multiple switching could reflect confusion and was relatively infrequent in our data (less than $5 \%$ of the responses).

${ }^{9}$ In our design, we can only identify the interval in which the probability lies, which has a width of $5 \%$. One could make this more precise by including more bookies, thus allowing for more granularity.

${ }^{10}$ Internet Appendix $\mathrm{C}$ displays a typical lottery pair.
} 
FIGURE 1

The Betting Sheet Used by the Subjects

Figure 1 shows the betting sheet that subjects used to place their bets (a nontransferable stake of £3 for each bookie) after each signal. The sheet lists 19 hypothetical bookies who offer different odds on the white or blue box being chosen.

\begin{tabular}{|c|c|c|c|c|c|c|c|}
\hline \multirow{2}{*}{ Bookie } & \multirow{2}{*}{ Stake } & \multicolumn{2}{|c|}{ Odds offered } & \multicolumn{2}{|c|}{$\begin{array}{l}\text { Earnings, including } \\
\text { the stake of } £ 3\end{array}$} & \multirow{2}{*}{\multicolumn{2}{|c|}{$\begin{array}{l}\text { I will bet on } \\
\text { (circle) }\end{array}$}} \\
\hline & & White & Blue & White & Blue & & \\
\hline 1 & $£ 3$ & 20.00 & 1.05 & $£ 60.00$ & $£ 3.15$ & W & B \\
\hline 2 & $£ 3$ & 10.00 & 1.11 & $£ 30.00$ & $£ 3.33$ & W & $B$ \\
\hline 3 & $£ 3$ & 6.67 & 1.18 & $£ 20.00$ & $£ 3.54$ & W & B \\
\hline 4 & $£ 3$ & 5.00 & 1.25 & $£ 15.00$ & $£ 3.75$ & W & B \\
\hline 5 & $£ 3$ & 4.00 & 1.33 & $£ 12.00$ & $£ 4.00$ & W & B \\
\hline 6 & $£ 3$ & 3.33 & 1.43 & $£ 10.00$ & $£ 4.29$ & W & $\mathrm{B}$ \\
\hline 7 & $£ 3$ & 2.86 & 1.54 & $£ 8.58$ & $£ 4.62$ & W & B \\
\hline 8 & $£ 3$ & 2.50 & 1.67 & $£ 7.50$ & $£ 5.00$ & W & $B$ \\
\hline 9 & $£ 3$ & 2.22 & 1.82 & $£ 6.66$ & $£ 5.46$ & W & B \\
\hline 10 & $£ 3$ & 2.00 & 2.00 & $£ 6.00$ & $£ 6.00$ & W & B \\
\hline 11 & $£ 3$ & 1.82 & 2.22 & $£ 5.46$ & $£ 6.66$ & W & $B$ \\
\hline 12 & $£ 3$ & 1.67 & 2.50 & $£ 5.00$ & $£ 7.50$ & W & B \\
\hline 13 & $£ 3$ & 1.54 & 2.86 & $£ 4.62$ & $£ 8.58$ & W & $\mathrm{B}$ \\
\hline 14 & $£ 3$ & 1.43 & 3.33 & $£ 4.29$ & $£ 10.00$ & W & B \\
\hline 15 & $£ 3$ & 1.33 & 4.00 & $£ 4.00$ & $£ 12.00$ & W & B \\
\hline 16 & $£ 3$ & 1.25 & 5.00 & $£ 3.75$ & $£ 15.00$ & W & B \\
\hline 17 & $£ 3$ & 1.18 & 6.67 & $£ 3.54$ & $£ 20.00$ & W & B \\
\hline 18 & $£ 3$ & 1.11 & 10.00 & $£ 3.33$ & $£ 30.00$ & W & B \\
\hline 19 & $£ 3$ & 1.05 & 20.00 & $£ 3.15$ & $£ 60.00$ & W & $B$ \\
\hline
\end{tabular}

To control for order effects, which are common in experiments (Harrison, Johnson, McInnes, and Rutström (2005)), the risk task preceded the belief task in half of the sessions; in the remaining half, the order was reversed. In addition, in the belief task, in half of the sessions, the samples were presented in ascending sequence (i.e., $N=3$, then $N=5$, etc.); in the other half, they were presented in descending order $(N=17$, then $N=9$, etc. $)$. Overall, we thus have a $2 \times 2$ experimental design.

In Figure 2, we plot the distribution of midpoints for the intervals that contain our subjects' risk-neutral subjective probabilities. Each panel plots the distribution of average midpoints after signals that differ in weight $(N)$ and that are associated 
FIGURE 2

The Distribution of Switch Points for Different Signals with the Same Posterior

Figure 2 presents the distribution of risk-neutral probabilities, grouped according to Bayesian posterior (6 cases) and signal weight (number of dice rolled, $N$ ). The solid vertical line in each graph depicts the Bayesian probability.
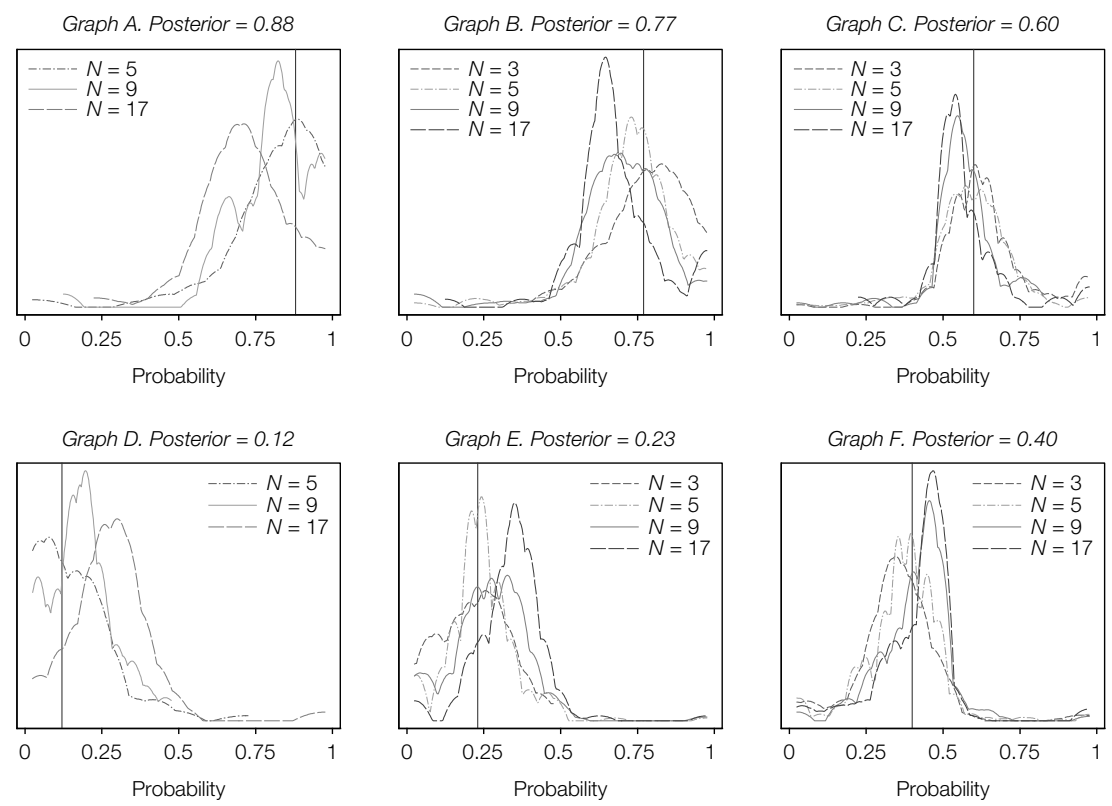

with a specific posterior. We have 6 posterior groups in total, $0.88,0.77$, and 0.6 when $w>b$, and by symmetry, $0.12,0.23$, and 0.4 when $b>w$. The vertical line in each panel shows the correct Bayesian probability. The distributions shown in Figure 2 appear to be systematically related to the strength-weight characteristics of the signals observed. In each posterior group, the distributions related to larger dice samples appear to have a lower mean, which implies that, holding the posterior constant, higher-weight signals elicit weaker responses, as predicted by GT (1992).

In the next section, we formally test the strength-weight hypothesis using a structural EUT model that assumes that the bets with the different bookies are evaluated according to equation (1). We use the maximum likelihood method to estimate the subjective probabilities and risk attitudes that best describe subjects' choices in both the risk and the belief task, and we test whether the strengthweight hypothesis is supported. To examine how assumptions about risk preferences affect inferences on the bias, we first estimate subjective probabilities by assuming RN and then by controlling for nonlinear utility (SEU). The econometric details of the model are provided in Internet Appendix D. 


\section{Results}

\section{A. Experimental Results}

Panel A of Table 1 contains estimates for the coefficient of risk attitude, $r$, and the behavioral error term, $\mu .{ }^{11}$ In columns 5-10, we have elicited subjective probabilities for different models of choice (RN vs. SEU), along with their associated standard errors. Subjective probabilities are grouped according to Bayesian posterior: $0.88,0.77$, and 0.6 . To ease exposition, we pool subjective probabilities for symmetric patterns (i.e., $(5,0)$ and $(0,5)) .{ }^{12}$ Column 2 in Panel B of Table 1 shows the composition of the signal, and columns 3 and 4 show its strength and weight characteristics. In both panels, the signals are arranged so that as one goes farther down the table, weight increases while strength decreases. ${ }^{13}$

We start the discussion with the RN model. For the high-strength, lowweight signal $(5,0)$, we find overreaction, with elicited probability higher than the Bayesian posterior probability by approximately $5 \%$. The elicited probability then drops for the $(7,2)$ signal to $90.6 \%$, and it drops even further for the $(11,6)$ signal to $79.7 \%$. The hypothesis that these subjective probabilities are equal is safely rejected ( $p$-value $<0.001$ ). This pattern supports the original GT (1992) findings, because subjective probabilities increase with signal strength, in violation of Bayes' rule. To get a sense of the magnitude of the bias, we can subtract subjective probabilities associated with the $(5,0)$ and $(11,6)$ signals, which yields $92.5 \%-79.5 \%=13 \%$. We find similar patterns of the remaining groups of 0.77 and 0.6 , with biases of $13.3 \%$ and $6.9 \%$, respectively, which are all statistically significant. ${ }^{14}$ Columns 6 and 8 ("Relative Bias") show the corresponding bias associated with each probability as a proportion of the required update from the prior of 0.5 , along with the overreaction for low-weight signals and underreaction for high-weight signals.

In the second model (SEU), the coefficient of risk attitude is equal to 0.562 and is highly statistically significant, indicating risk aversion. The magnitude of risk aversion obtained is similar to that in other experiments with similar stakes, as reviewed by Harrison and Rutström (2008). As in the RN case, subjective probabilities in all the Bayesian posterior groups increase with signal strength, and the differences between the high-strength, low-weight and low-strength, high-weight probabilities are statistically significant. However, the striking result from this analysis is that once we allow for risk aversion, the magnitude of the bias halves.

\footnotetext{
${ }^{11}$ The behavioral parameter $\mu$ is a structural "noise parameter" and is used to allow for some errors from the perspective of the deterministic EUT model. Specifically, $\mu>0$ captures cases where the option with the lower expected utility might be chosen by accident.

${ }^{12}$ For example, if the subjective probability for white estimated after a pattern of 5 white and 0 blue is $\pi_{1}$ with standard error $\sigma\left(\pi_{1}\right)$, and the probability for white elicited after a pattern of 0 white and 5 blue is $\pi_{2}$ with standard error $\sigma\left(\pi_{2}\right)$, we report the average of $\pi_{1}$ and $1-\pi_{2}$, using the delta method to derive its standard error.

${ }^{13} \mathrm{We}$ did not include in Table 1 dice combinations that emerged that did not have equivalents in the original GT (1992) design.

${ }^{14}$ Kraemer and Weber (2004) also tested the GT (1992) effect, using stated-preference methods of elicitation and hypothetical information signals. Their results were in line with the original GT findings but did not allow a comparison of the general magnitude of the bias, because Kraemer and Weber (2004) restricted their analysis to hypothetical signals that always yielded a posterior of 0.6.
} 
TABLE 1

\section{Estimated Subjective Probabilities}

Table 1 reports subjective probabilities and preference parameters estimated with maximum likelihood. Subjective probabilities are constrained to lie in the unit interval, using the transform $\pi=1 /(1+\exp (\kappa))$, where $\kappa$ is the parameter estimated, and $\pi$ is the inferred probability. We report the average probability elicited after symmetric signals $($ e.g., $(5,0)$ and $(0,5))$, using the delta method to estimate the standard error for pooled $\pi$ from estimates of $\kappa$. We employ "frequency weights" of 50 for every observed choice from the risk task to ensure that the estimated risk parameters are based primarily on the choices from the risk tasks. In the RN column, we estimate the model by assuming risk neutrality (constraining $r=0.0001$ ). In the SEU column, we remove this constraint and allow risk aversion, assuming a CRRA utility function of the type $y^{1-r} /(1-r) . \mu$ is a structural error parameter, and $\pi$ is the subjective probability. RELATIVE_BIAS is calculated as $\pi /$ BAYESIAN_POSTERIOR. Columns 9 and 10 indicate the standard errors of estimated parameters $(r, \mu$, and $\pi)$, using the delta method. Standard errors are also clustered at the subject level. The econometric procedure employed is explained in detail in Internet Appendix D.

Panel A. Preference Parameters

Panel B. Probabilities

BAYESIAN_POSTERIOR Signal Weight Strength 0.88
0.88

0.88
0.88

Bias (High - Low)

$p$-value

0.77

0.77

0.77

0.77

Bias (High - Low)

$p$-value

0.60

0.60

0.60

0.60

Bias (High - Low) p-value

$(4,1) \quad 5$

$\begin{array}{llll}(2,1) & 3 & 0.33 & 0.714\end{array}$

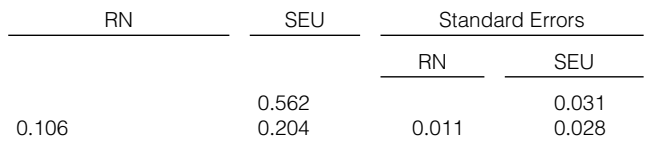

RELATIVE_BIAS

$\pi \quad$ RELATIVE_BIAS Standard Errors

$\begin{array}{llll}0.706 & 0.80 & 0.025 & 0.019\end{array}$

$\begin{array}{lrlllllll}(7,2) & 9 & 0.56 & 0.906 & 1.03 & 0.693 & 0.79 & 0.018 & 0.015 \\ (11,6) & 17 & 0.29 & 0.797 & 0.91 & 0.631 & 0.72 & 0.029 & 0.014\end{array}$

$\begin{array}{lrlllllll}(7,2) & 9 & 0.56 & 0.906 & 1.03 & 0.693 & 0.79 & 0.018 & 0.015 \\ (11,6) & 17 & 0.29 & 0.797 & 0.91 & 0.631 & 0.72 & 0.029 & 0.014\end{array}$

$7.05 \%$

$\begin{array}{lr}13.00 \% & 7.05 \% \\ <0.001 & <0.001\end{array}$

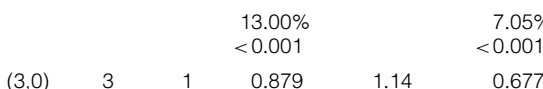

$\begin{array}{lrrrrrr}(3,0) & 3 & 1 & 0.879 & 1.14 & 0.677 & 0.88\end{array}$

$\begin{array}{llll}0.643 & 0.84 & 0.017 & 0.011\end{array}$

$\begin{array}{llll}0.620 & 0.81 & 0.032 & 0.013\end{array}$

$\begin{array}{llll}0.601 & 0.78 & 0.018 & 0.009\end{array}$

$\begin{array}{lllllll}0.33 & 0.767 & 1.00 & 0.620 & 0.81 & 0.032 & 0.013 \\ 0.18 & 0.746 & 0.97 & 0.601 & 0.78 & 0.018 & 0.009\end{array}$

$13.30 \% \quad 7.60 \%$

$<0.001<0.001$

$\begin{array}{llll}0.584 & 0.97 & 0.022 & 0.009\end{array}$

$\begin{array}{llll}0.563 & 0.94 & 0.013 & 0.006\end{array}$

$\begin{array}{rrrrrrrrr}(5,4) & 9 & 0.11 & 0.590 & 0.98 & 0.541 & 0.90 & 0.017 & 0.007 \\ (9,8) & 17 & 0.06 & 0.645 & 1.08 & 0.549 & 0.92 & 0.021 & 0.008\end{array}$

$\begin{array}{lrlllllll}(5,4) & 9 & 0.11 & 0.590 & 0.98 & 0.541 & 0.90 & 0.017 & 0.007 \\ (9,8) & 17 & 0.06 & 0.645 & 1.08 & 0.549 & 0.92 & 0.021 & 0.008\end{array}$

Specifically, for the 0.88 group, the bias is $7 \%$ instead of $13.0 \%$; for the 0.77 group, it is $7.6 \%$ instead of $13.3 \%$; and for the 0.6 group, it is $3.5 \%$ instead of $6.9 \%$. This highlights the fact that inferences about the strength-weight effect under the assumption of $\mathrm{RN}$ are likely to overstate the bias. ${ }^{15}$

How do our results compare with the original findings of GT (1992)? Across all 3 patterns, the average bias reported by GT is $20.6 \% .^{16}$ The corresponding average bias in our analysis is only $6 \%$ ( $p$-value $<0.001$ ) when we allow for nonlinear utility. The hypothesis that the average bias in the two studies is equal is safely rejected ( $p$-value $<0.001$ ). This comparison suggests that the bias is significantly reduced when tested under experimental designs that incentivize responses, which

\footnotetext{
${ }^{15}$ In unreported results, we derive results using a rank-dependent utility model that accounts for both nonlinear utility and probability weighting via nonadditive decision weights. The results show that our subjects do not engage in probability weighting; therefore, inferences regarding the strengthweight bias from this model are identical to those drawn from the SEU model. These results are available from the authors.

${ }^{16}$ For the 0.88 case, GT ((1992), p. 415, Table 1) report a bias of $28 \%(92.5-64.5 \%)$, for the 0.77 group a bias of $25.5 \%(85 \%-59.5)$, and for the 0.6 group a bias of $8.5 \%(63 \%-54.5 \%)$.
} 
has important implications for inferences about the relevance of the strengthweight bias to stock market anomalies.

GT (1992) report that their subjects overreact to high-strength, low-weight information, stating probabilities that are higher than those implied by Bayes' rule. In our estimations, we find evidence of overreaction toward high-strength, low-weight signals only when we constrain $r$ to RN. When we allow for nonlinear utility, we find a general tendency of underreaction, or conservatism (Edwards (1968)) toward sample information, as subjective probabilities are lower than Bayesian posterior probabilities (RELATIVE_BIAS is less than 1 in all cases). Moreover, in each posterior group, underreaction is higher when the signal is of high weight. For example, in the SEU model, for signals that imply a posterior of 0.88 , underreaction is $25 \%$ when the signal is of high weight (RELATIVE_BIAS $=0.72$ ) and $18 \%$ when it is of low weight (RELATIVE_BIAS $=0.8$ ). This finding can provide an explanation for prices adjusting slowly to important, high-weight information, such as earnings surprises (Bernard and Thomas (1989)) or changes in dividend policy (Michaely et al. (1995)).

We continue to more formally test the strength-weight hypothesis by estimating the following model: ${ }^{17}$

$$
\ln \{\ln (\pi /(1-\pi)) / \ln (0.6 / 0.4)\} \quad=\quad \alpha \ln N+\beta \ln S .
$$

Bayes' rule predicts that the coefficients on strength $(\beta)$ and weight $(\alpha)$ should both be equal to 1 , whereas $\beta>\alpha$ under the strength-weight hypothesis. The results, which are shown in Panel A of Table 2, show that the coefficient on weight, $\alpha$, is 0.442 and on strength, $\beta$, is 0.736 , which shows that signal strength affects probabilities more than signal weight, in line with our previous results in Table 1 . The hypotheses that $\alpha=\beta$ is safely rejected ( $p$-value $<0.001$ ). We can define the total bias as $1-\alpha / \beta$, equal to $40 \%$ in our data, again significantly smaller than the corresponding bias of $62 \%$ reported by GT (1992) $(p$-value $<0.001){ }^{18}$

We also use this model to test whether the strength-weight bias differs among subjects with different demographic characteristics. Previous research found that female subjects are less likely to behave as Bayesians in similar experimental tasks (Charness and Levin (2005)). We therefore condition estimates of $\alpha$ and $\beta$ on the dummy FEMALE. Moreover, subjects who have knowledge of statistics have been found to behave more rationally in such quantitative tasks (Halevy (2007)). To test for this effect, we condition estimates of $\alpha$ and $\beta$ on the dummy MATH, which takes a value of 1 if the subject is studying in a quantitative field, and 0 otherwise. Subjects with higher cognitive abilities have also been shown to act more rationally (Grinblatt, Keloharju, and Linnainmaa (2012)). As a proxy for quantitative ability, we define the proxy FIRST_CLASS, which takes a value of 1 if the subject's self-reported average marks to date are in the highest class, and 0 otherwise. ${ }^{19}$ Finally, experienced subjects have been shown to act

\footnotetext{
${ }^{17}$ This entails expressing the subjective probabilities within the structural model in terms of strength and weight and then estimating $\alpha$ and $\beta$ using maximum likelihood. Internet Appendix D explains this procedure, and Internet Appendix E derives equation (2) from Bayes' rule.

${ }^{18} \mathrm{GT}((1992), \mathrm{p} .416)$ report that in their experiment, $\alpha$ is 0.31 , and $\beta$ is 0.81 .

${ }^{19}$ In the U.K., this is $70 \%$ and above and is achieved by roughly $15 \%-20 \%$ of students.
} 
TABLE 2

The Effect of Strength and Weight on Subjective Probabilities

\begin{tabular}{|c|c|c|c|c|c|c|}
\hline & \multicolumn{2}{|c|}{ Panel A. SEU } & \multicolumn{2}{|c|}{$\begin{array}{c}\text { Panel B. SEU } \\
\text { and Demographics }\end{array}$} & \multicolumn{2}{|c|}{$\begin{array}{c}\text { Panel C. SEU } \\
\text { and Order Effects }\end{array}$} \\
\hline & Coeff. & Std. Error & Coeff. & Std. Error & Coeff. & Std. Error \\
\hline$\alpha$ & 0.442 & 0.040 & 0.554 & 0.078 & 0.420 & 0.068 \\
\hline $\begin{array}{l}\text { FEMALE } \\
\text { MATH } \\
\text { FIRST_CLASS } \\
\text { EXPERIENCE } \\
\text { RA_THEN_B } \\
\text { B_DESCENDING }\end{array}$ & & & $\begin{array}{r}-0.167 \\
-0.106 \\
0.068 \\
-0.022\end{array}$ & $\begin{array}{l}0.080 \\
0.080 \\
0.091 \\
0.036\end{array}$ & $\begin{array}{r}0.058 \\
-0.011\end{array}$ & $\begin{array}{l}0.076 \\
0.069\end{array}$ \\
\hline$\beta$ & 0.737 & 0.043 & 0.827 & 0.095 & 0.689 & 0.090 \\
\hline $\begin{array}{l}\text { FEMALE } \\
\text { MATH } \\
\text { FIRST_CLASS } \\
\text { EXPERIENCE } \\
\text { RA_THEN_B } \\
\text { B_DESCENDING }\end{array}$ & & & $\begin{array}{r}-0.042 \\
-0.195 \\
0.088 \\
-0.014\end{array}$ & $\begin{array}{l}0.097 \\
0.099 \\
0.117 \\
0.064\end{array}$ & $\begin{array}{l}0.047 \\
0.048\end{array}$ & $\begin{array}{l}0.092 \\
0.089\end{array}$ \\
\hline$r$ & 0.567 & 0.030 & 0.518 & 0.051 & 0.609 & 0.032 \\
\hline $\begin{array}{l}\text { FEMALE } \\
\text { MATH } \\
\text { FIRST_CLASS } \\
\text { RA_THEN_B }\end{array}$ & & & $\begin{array}{r}0.122 \\
-0.029 \\
0.011\end{array}$ & $\begin{array}{l}0.047 \\
0.045 \\
0.041\end{array}$ & -0.098 & 0.041 \\
\hline$\mu$ & 0.208 & 0.029 & 0.207 & 0.028 & 0.202 & 0.026 \\
\hline
\end{tabular}

more rationally, both in experiments (Loomes, Starmer, and Sugden (2003)) and in the field (Seru, Shumway, and Stoffman (2010)). Although our experiment did not provide any feedback, it is possible that subjects learn about the latent process by observing which samples are more or less frequent. To test for such learning, we define the dummy EXPERIENCE, which takes a value of 1 for the last 15 rounds of the belief task, and 0 otherwise. We estimate model 10 by conditioning $\alpha$ and $\beta$ on these dummies. We also condition $r$ on FEMALE, MATH, and FIRST_CLASS, because these variables may also affect risk attitudes.

The results are shown in Panel B of Table 2. The entry next to each variable shows its marginal contribution and its associated standard error. We find that females are significantly more risk averse, consistent with prior studies. Females are found to be less sensitive to signal weight (coefficient of -0.167 with standard error 0.08), which suggests that their beliefs are more biased. Subjects who study in quantitative fields respond less strongly to signal strength (coefficient of -0.195 with standard error 0.098), which suggests that their beliefs are less biased. These effects are statistically significant at the 5\% level. Overall, the analysis in Panel B suggests that the strength-weight bias is likely to be stronger among females and subjects with no quantitative skills but also that no group of subjects is completely immune to the strength-weight effect. 
Finally, we examine whether order effects influence our results by allowing estimates of $\alpha$ and $\beta$ to differ depending on whether the risk task is conducted first (RA_THEN_B $=1$ ) and depending on whether the samples are presented in descending order in the belief task (B_DESCENDING $=1$ ). We find that our estimates of $\alpha$ and $\beta$ are not affected by order effects. However, we find that subjects become more risk averse if the risk task is conducted first.

\section{B. Asset Pricing Simulations}

Our findings suggest that the strength-weight bias is weaker than that reported by GT (1992) and that subjects are more likely to underreact rather than overreact. To examine the effect of these findings on asset pricing, we recalibrate the model proposed by Barberis et al. (1998) to parameters that imply such changes.

BSV (1998) note that earnings are generated by a random-walk process, but the investor falsely believes in either a mean-reverting regime (underreaction) or a trending-regime (overreaction). There are some probabilities that govern the transition from one model to the other, which can be thought to relate to the strengthweight effect (i.e., the switch from underreaction to overreaction). The investor observes past earnings realizations to determine which model is generating earnings; after a short string of surprises of the same sign, which appear relatively "unconvincing," the investor underreacts. As this string increases and becomes more salient, the investor overreacts. BSV use this model to simulate the returns of portfolios of firms with $n$ consecutive positive or negative shocks (where $n$ ranges from 1 to 4 ) and show that the return differential between these portfolios, $r_{+}^{n}-r_{-}^{n}$, decreases in $n$. Moreover, for short strings $(n=1,2)$, it is positive, indicating underreaction, and it turns negative for longer strings $(n=3,4)$, indicating overreaction.

Following this procedure, we examine how changes in the transition probabilities, such that the investor always relies more on model 1 , affect $r_{+}^{n}-r_{-}^{n} .^{20} \mathrm{We}$ find that $r_{+}^{n}-r_{-}^{n}$ decreases with $n$ but at a generally smaller rate. Moreover, $r_{+}^{n}-r_{-}^{n}$ is larger for all $n$, and it requires a longer string of news to actually turn it negative. Overall, our experimental findings, as calibrated through the BSV (1998) model, imply more widespread underreaction in asset prices.

\section{Conclusion}

Griffin and Tversky (1992) propose the strength-weight hypothesis, which is that decision makers are more responsive to the extremity (strength) of the information than to its predictive validity (weight), even when both strength and weight are equally diagnostic. This hypothesis is used in many applications in finance.

We test whether the hypothesis holds by means of an experiment that allows us to infer subjective probabilities through betting decisions with real monetary incentives. We provide respondents with imperfect information about the true state of the world and ask them to reveal their subjective beliefs about the likelihood of

\footnotetext{
${ }^{20}$ This analysis is available in Internet Appendix F.
} 
the true state by making a series of bets, according to the logic of Savage (1954), (1971) and Ramsey (1931).

Our results broadly support the original findings of GT (1992); decision makers generally perceive events as more likely when the available evidence has high strength and low weight. However, the magnitude of the bias we find is less than a third of that reported by GT, which suggests that the impact of the strength-weight bias on stock market anomalies is likely to be smaller than what the original estimates suggest.

\section{References}

Andersen, S.; J. Fountain; G. W. Harrison; and E. E. Rutström. "Estimating Subjective Probabilities." Journal of Risk and Uncertainty, 48 (2014), 207-229.

Andersen, S.; G. W. Harrison; M. I. Lau; and E. E. Rutström. "Discounting Behavior and the Magnitude Effect: Evidence from a Field Experiment in Denmark." Economica, 80 (2013), 670-697.

Antoniou, C.; G. W. Harrison; M. I. Lau; and D. Read. "Subjective Bayesian Beliefs." Journal of Risk and Uncertainty, 50 (2015), 35-59.

Asparouhova, E.; M. Hertzel; and M. Lemmon. "Inference from Streaks in Random Outcomes: Experimental Evidence on Beliefs in Regime Shifting and the Law of Small Numbers." Management Science, 55 (2009), 1766-1782.

Barberis, N.; A. Shleifer; and R. Vishny. "A Model of Investor Sentiment." Journal of Financial Economics, 49 (1998), 307-343.

Bernard, V. L., and J. K. Thomas. "Post-Earnings-Announcement Drift: Delayed Price Response or Risk Premium?” Journal of Accounting Research, 27 (1989), 1-36.

Bloomfield, R., and J. Hales. "Predicting the Next Step of a Random Walk: Experimental Evidence of Regime-Shifting Beliefs.” Journal of Financial Economics, 65 (2002), 397-414.

Bondarenko, O., and P. Bossaerts. "Expectations and Learning in Iowa." Journal of Banking and Finance, 24 (2000), 1535-1555.

Cason, T. N., and C. R. Plott. "Misconceptions and Game Form Recognition of the BDM Method: Challenges to Theories of Revealed Preference and Framing." Journal of Political Economy, 122 (2014), 1235-1270.

Charness, G., and D. Levin. "When Optimal Choices Feel Wrong: A Laboratory Study of Bayesian Updating, Complexity, and Affect.” American Economic Review, 95 (2005), 1300-1309.

Charness, G.; E. Karni; and D. Levin. "On the Conjunction Fallacy in Probability Judgment: New Experimental Evidence Regarding Linda.” Games and Economic Behavior, 68 (2010), 551-556.

Conlisk, J. "Three Variants on the Allais Example." American Economic Review, 79 (1989), 392-407.

Costa-Gomes, M. A., and G. Weizsäcker. "Stated Beliefs and Play in Normal-Form Games." Review of Economic Studies, 75 (2008), 729-762.

Daniel, K., and S. Titman. "Market Reactions to Tangible and Intangible Information." Journal of Finance, 61 (2006), 1605-1643.

de Dreu, J., and J. A. Bikker. "Investor Sophistication and Risk Taking." Journal of Banking and Finance, 36 (2012), 2145-2156.

Edwards, W. "Conservatism in Human Information Processing." In Formal Representation of Human Judgment, B. Kleinmutz, ed. New York, NY: Wiley (1968), 17-52.

Fiore, S. M.; G. W. Harrison; C. E. Hughes; and E. E. Rutström. "Virtual Experiments and Environmental Policy." Journal of Environmental Economics and Management, 57 (2009), 65-86.

Gilboa, I.; A. W. Postlewaite; and D. Schmeidler. "Probability and Uncertainty in Economic Modeling." Journal of Economic Perspectives, 22 (2008), 173-188.

Grether, D. M. "Bayes' Rule as a Descriptive Model: The Representativeness Heuristic." Quarterly Journal of Economics, 95 (1980), 537-557.

Griffin, D., and A. Tversky. "The Weighing of Evidence and the Determinants of Confidence." Cognitive Psychology, 24 (1992), 411-435.

Grinblatt, M.; M. Keloharju; and J. Linnainmaa. "IQ, Trading Behavior, and Performance.” Journal of Financial Economics, 104 (2012), 339-362.

Gupta-Mukherjee, S. "Investing in the 'New Economy': Mutual Fund Performance and the Nature of the Firm.” Journal of Financial and Quantitative Analysis, 49 (2013), 1-42.

Hackbarth, D. "Determinants of Corporate Borrowing: A Behavioral Perspective." Journal of Corporate Finance, 15 (2009), 389-411.

Halevy, Y. "Ellsberg Revisited: An Experimental Study.” Econometrica, 75 (2007), 503-536. 
Harrison, G. W.; E. Johnson; M. M. McInnes; and E. E. Rutström. "Risk Aversion and Incentive Effects: Comment.” American Economic Review, 95 (2005), 897-901.

Harrison, G. W., and E. E. Rutström. "Risk Aversion in the Laboratory." In Risk Aversion in Experiments, J. C. Cox and G. W. Harrison, eds. Bingley, U.K.: Emerald (2008), 41-196.

Hey, J. D., and C. Orme. "Investigating Generalizations of Expected Utility Theory Using Experimental Data.” Econometrica, 62 (1994), 1291-1326.

Kadane, J. B., and R. L. Winkler. "Separating Probability Elicitation from Utilities." Journal of the American Statistical Association, 83 (1988), 357-363.

Kraemer, C., and M. Weber. "How Do People Take into Account Weight, Strength and Quality of Segregated vs. Aggregated Data? Experimental Evidence." Journal of Risk and Uncertainty, 29 (2004), 113-142.

Kuhnen, C. M. "Asymmetric Learning from Financial Information.” Journal of Finance, 70 (2015), 2020-2062.

Kuhnen, C. M., and B. Knutson. "The Influence of Affect on Beliefs, Preferences, and Financial Decisions." Journal of Financial and Quantitative Analysis, 46 (2011), 605-626.

Laury, S. K.; M. M. McInnes; and J. T. Swarthout. "Insurance Decisions for Low-Probability Losses." Journal of Risk and Uncertainty, 39 (2009), 17-44.

Liang, L. "Post-Earnings Announcement Drift and Market Participants' Information Processing Biases." Review of Accounting Studies, 8 (2003), 321-345.

Loomes, G.; C. Starmer; and R. Sugden. "Do Anomalies Disappear in Repeated Markets?” Economic Journal, 113 (2003), 153-166.

Michaely, R.; R. H. Thaler; and K. L. Womack. "Price Reactions to Dividend Initiations and Omissions: Overreaction or Drift?” Journal of Finance, 50 (1995), 573-608.

Plott, C. R., and K. Zeiler. "The Willingness to Pay-Willingness to Accept Gap." American Economic Review, 95 (2005), 530-545.

Puetz, A., and S. Ruenzi. "Overconfidence among Professional Investors: Evidence from Mutual Fund Managers." Journal of Business Finance and Accounting, 38 (2011), 684-712.

Ramsey, F. P. Truth and Probability. The Foundations of Mathematics and Other Logical Essays. London, U.K.: Routledge and Kegan Paul (1931).

Rutström, E. E., and N. T. Wilcox. "Stated Beliefs versus Inferred Beliefs: A Methodological Inquiry and Experimental Test." Games and Economic Behavior, 67 (2009), 616-632.

Savage, L. J. The Foundations of Statistics. New York, NY: Wiley (1954).

Savage, L. J. "Elicitation of Personal Probabilities and Expectations." Journal of the American Statistical Association, 66 (1971), 783-801.

Seru, A.; T. Shumway; and N. Stoffman. "Learning by Trading." Review of Financial Studies, 23 (2010), 705-739.

Smith, V. L. "Microeconomic Systems as an Experimental Science." American Economic Review, 72 (1982), 923-955.

Sorescu, S., and A. Subrahmanyam. "The Cross Section of Analyst Recommendations." Journal of Financial and Quantitative Analysis, 41 (2006), 139-168. 